\title{
АНАЛИЗ ПЛАНИРОВАНИЯ И ОЦЕНКА РЕАЛИЗАЦИИ МУНИЦИПАЛЬНЫХ ПРОГРАММ В СОЦИАЛЬНОЙ СФЕРЕ ГОРОДА ЭЛИСТА
}

\author{
(C) 2021 г. Н. Л. Курепина, Г. В. Баглеева, Т. Н. Асанов
}

\author{
Калмыцкий государственный университет имени Б. Б. Городовикова, \\ 2. Элиста, Россия
}

Целью исследования является анализ планирования и реализаџии мунициипальных программ сочиальной направленности города Элиста.

Методологической основой данного исследования являются общенаучные методы, методы экономического анализа, планирования и моделирования.

Результаты исследования. Проведенные исследования показали, что в муниципальном образовании на протяжении последних лет происходил переход на программно-иелевое планирование. Анализ доходной части бюджета, сформированного в соответствии с бюджетной классификацией, показал, что за последние годы налоговые поступления не являются основным источником формирования бюджета города, они составляли только четверть поступлений, более $50 \%$ - безвозмезднье поступления. Структура расходов утверждается по ведомствам и изелевым статьям муниципальных программ. Более $70 \%$ расходов направлено на развитие сочиильной сферы, поэтому при исследовании мы сделали акиент именно на этой статье расходов, наиболее важной для развития муниципалитета. Расходы на образование занимают более половины от общего объема расходов бюджета. Финансовые средства на другие программы сочиального развития, развитие культуры, физической культуры, спорта, сочиальную поддержку граждан занимают всего около 8\%.

Перспектива исследования. Результаты исследования показали, что при оценке реализации программ нет четкого формирования показателей, позволяющих оценить эффективность исполнения обязательств, необходимо совершенствование методики оченки эффективности реализации муниципальных программ. Совершенствование методических подходов оценки результатов реализачии программ является одним из направлений, требующих дальнейшего исследования.

Ключевые слова: муниципальный бюджет; мунищипальные программы; программноцелевой метод; индикаторы оценки.

\section{ANALYSIS OF PLANNING AND EVALUATION OF IMPLEMENTATION MUNICIPAL PROGRAMS IN THE SOCIAL SPHERE CITIES OF ELISTA}

\author{
(C) 2021 N. L. Kurepina, G. V. Bagleeva, T. N. Asanov
}

\section{Kalmyk State University named after B. B. Gorodovikov, Elista, Russia}

The aim of the study is to analyze the planning and implementation of municipal programs of social orientation in the city of Elista.

The methodological basis of this research is general scientific methods, methods of economic analysis, planning and modeling. 
Research results. The studies carried out have shown that in the municipality over the past years there has been a transition to program-targeted planning. An analysis of the revenue side of the budget, formed in accordance with the budget classification, showed that in recent years tax receipts are not the main source of the city's budget formation, they accounted for only a quarter of receipts, more than $50 \%$ are gratuitous receipts. The structure of expenses is approved by departments and by target items of municipal programs. More than $70 \%$ of expenditures are directed to the development of the social sphere, therefore, in our research, we focused on this expenditure item, which is the most important for the development of the municipality. Expenditures on education account for more than half of the total budget expenditures. Financial resources for other programs of social development, development of culture, physical culture, sports, social support of citizens account for only about $8 \%$.

Research perspective. The results of the study showed that when assessing the implementation of programs, there is no clear formation of indicators that allow assessing the effectiveness of the fulfillment of obligations, it is necessary to improve the methodology for assessing the effectiveness of the implementation of municipal programs. Improving methodological approaches to assessing the results of the implementation of programs is one of the areas requiring further research.

Key words: municipal budget; municipal programs; target program method; assessment indicators.

Введение. Муниципальные финансы являются составной частью финансовой системы Российской Федерации. Единая бюджетная система, включающая государственные и муниципальные финансы, позволяет реализовать функции финансов.

Муниципальные финансы как составная часть финансовой системы предназначены для финансирования расходов, необходимых для выполнения муниципальными образованиями возложенных на них функций. Они представляют собой совокупность денежных отношений, возникающих в ходе формирования и использования финансовых ресурсов.

На протяжении нескольких лет в России проходил процесс реформирования финансовых отношений, одним из направлений которого был переход на программно-целевое планирование.

Трансформация управления муниципальными финансами происходила сложно, длительно, и до сегодняшнего дня остаются нерешенными многие вопросы.

Обзор научно-исследовательской литературы. Понятия «программный бюджет», «программное бюджетирование», «программно-целевое планирование» рассматриваются авторами как инструменты планирования доходов и расходов муниципальных обра- зований, позволяющие повысить эффективность достижения целей и задач, определенных программами и подпрограммами [6].

Несомненно, данный метод позволяет более полно осуществлять функции финансов, такие как распределительная, регулятивная, контролирующая, однако имеются определенные недостатки, одним из которых можно отметить меньшую прозрачность программного бюджета, особенно в части оценки эффективности его исполнения [9].

Авторам для оценки степени достижения результата в процессе управления муниципальными финансами предлагаются различные методы и приемы. Так, по мнению А.С. Чулкова, «условием для эффективного распределения программных расходов может стать разработка процедуры мониторинга результативности бюджетных расходов, позволяющая контролировать достижение результатов не по факту окончания программы, а по ходу ее исполнения, и своевременно корректировать те или иные действия» $[9$, с. 21].

Наибольшее количество разногласий и критики вызывает система показателей результативности бюджетных программ [8].

Таким образом, проведенные исследования показали, что по-прежнему идут дискуссии и даются неоднозначные оценки программно-целевого планирования му- 
ниципальных бюджетов, но процесс идет и, по нашему мнению, одной из задач, требующих решения, является совершенствование оценки эффективности и качества выполнения муниципальных программ.

На современном этапе экономического развития в РФ уделяется много внимания развитию муниципальных образований, городской среды, разработаны программы для реализации и развития городских и сельских поселений, одной из них является создание комфортной среды. И здесь, несомненно, важная роль принадлежит муниципальным финансам, обеспечивающим не только социально-экономическое развитие, на которое предусмотрена основная часть бюджетных расходов (более 70\%), но и другие направления, такие как развитие городского хозяйства,

В соответствии с Бюджетным кодексом Российской Федерации [1] и бюджетной классификацией доходы бюджета города сгруппированы следующим образом:

- налоговые и неналоговые доходы;

— безвозмездные поступления.

Результаты исследования. Мы провели анализ формирования и исполнения бюджета муниципального образования города Элиста, выполнения программно-целевого бюджета в реализации программ социальной направленности, дали оценку результатов.

Анализ объема доходной части бюджета города Элиста за 2019 год по кодам бюджетной классификации показал, что налоговые и неналоговые доходы - 872,4 млн. руб. или $42,5 \%$, безвозмездные поступления 1181,5 млн. руб. или 58,5\%.

В структуре налоговых поступлений преобладает доля налогов на доходы физических лиц $(43,7 \%)$ и на имущество, в основном земельный налог $(28,6 \%)$ в общей сумме налоговых поступлений 2019 года (рис. 1).

Расходная часть бюджета муниципального образования города Элиста представлена ведомственной структурой и в разрезе девяти муниципальных программ. Основное внимание уделено социальному развитию города, поэтому в структуре расходов на программы социальной направленности предусмотрено $76,2 \%$ расходов (рис. 2).

Главным приоритетом формирования бюджета города Элиста на 2017-2019 гг. являлось сохранение стабильности финансирования социальной сферы.

В структуре расходов превалирует отрасль социального блока - образование, которое занимает $54,7 \%$ от общего объема расходов бюджета на 2017 год, 67,4\% на 2018 год, 70,1\% — на 2019 год [5].

Структура расходов в разрезе подпрограмм: на развитие дошкольного образования - 48,4\%, общего образования - 43,2\%, дополнительного образования - 5,2\%, предусмотрены также средства на организацию отдыха детей и реализацию программы (рис. 3).

Финансовые средства на другие программы социального развития, развитие культуры,

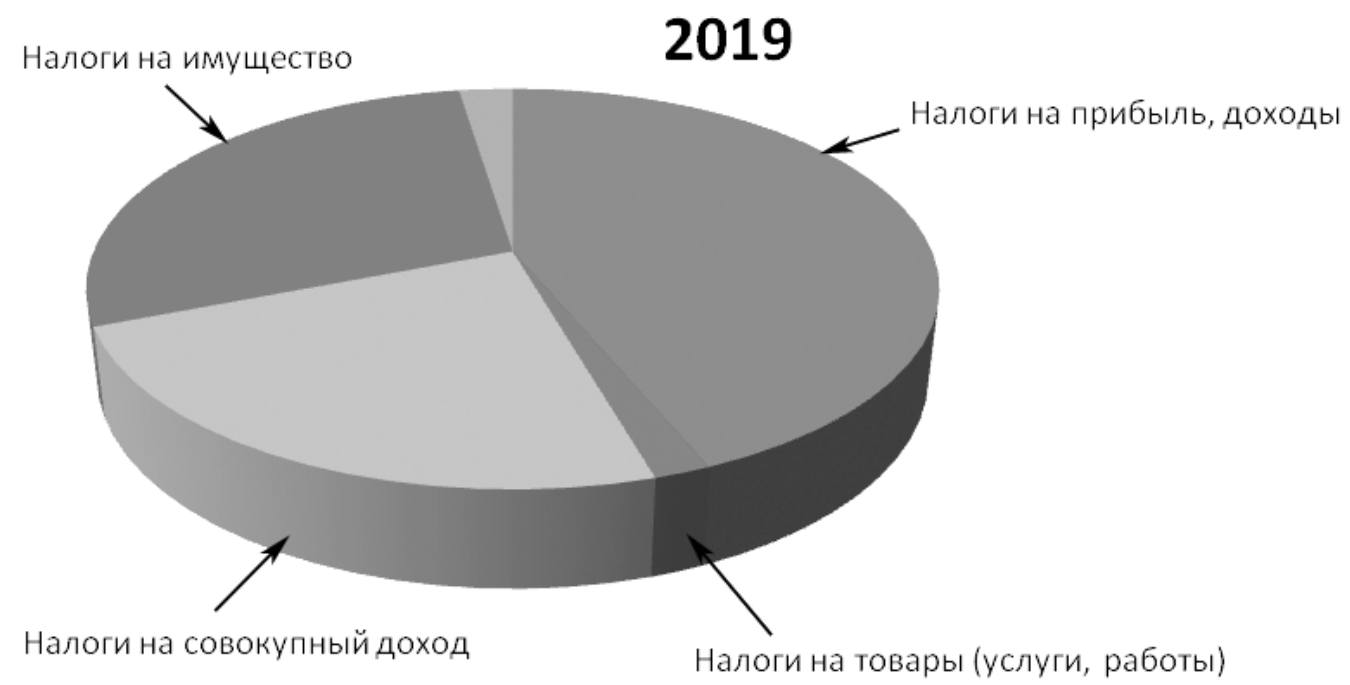

Рис. 1. Структура налоговых поступлений, \% 
физической культуры, спорта, социальную поддержку граждан в структуре социальных программ занимают всего около $8 \%$.

Проведенный анализ показал, что в муниципальном образовании планирование доходной и расходной части бюджета осуществляется в соответствии с утвержденными программами, ежегодно проводится контроль эффективности их выполнения.
В этих целях разработаны критерии оценки эффективности реализации муниципальных программ, и ежегодно Элистинским городским собранием рассматриваются достигнутые результаты.

По нашему мнению, данные показатели не отражают полной картины и не свидетельствуют об эффективности выполнения программы.
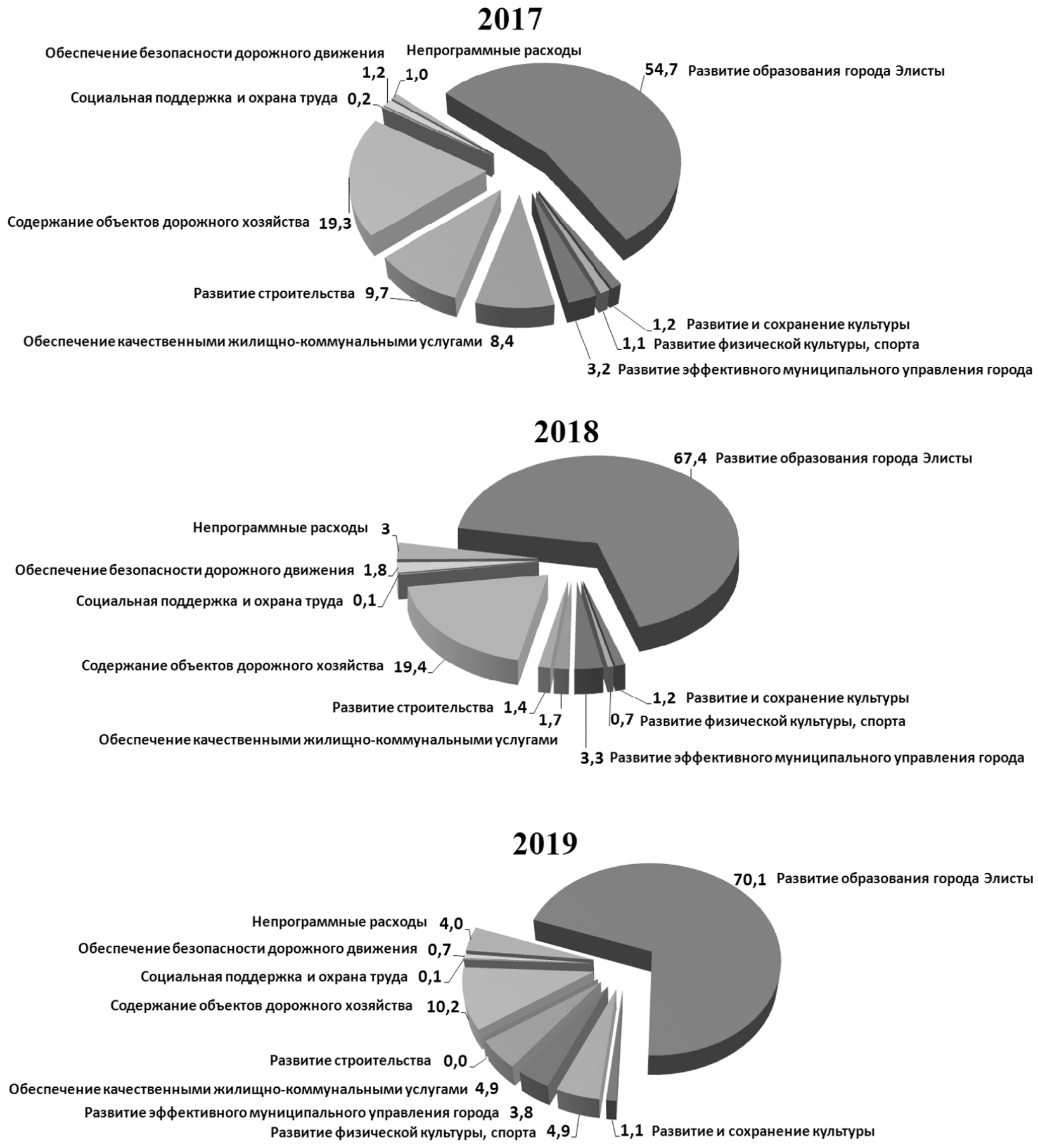

Рис. 2. Структура расходов программно-целевого бюджета города Элиста на 2017-2019 гг., млн. руб. 
Не всегда можно объективно определить и оценить данные целевые индикаторы, тем более что они никоим образом не отражают финансовую составляющую реализации программы, эффективности вложения финансовых средств при реализации целей данной программы, создания условий для эффективного развития системы образования, направленной на обеспечение доступности качественного образования.
Этот факт стал причиной корректировки паспорта муниципальной программы «Развитие образования города Элиста», определения новых целевых показателей.

Данные показатели охватывают более широкий спектр образовательных услуг, которые предусмотрены в муниципальной программе, обеспечивающей финансирование развития системы образования города Элиста. Это и дошкольное, и дополнительное

Целевые показатели муниципальной программы

Таблица 1 «Развитие образования города Элиста» на 2019-2024 гг.

\begin{tabular}{|c|l|c|c|c|}
\hline № & \multicolumn{1}{|c|}{2018 г. } & 2019 г. & 2020 г. \\
\hline 1 & $\begin{array}{l}\text { Количество мест в муниципальных дошкольных образова- } \\
\text { тельных учреждениях города Элиста }\end{array}$ & 7516 & 7826 & 7926 \\
\hline $\begin{array}{l}\text { Доля обучающихся МОО города Элиста, успешно освоив- } \\
\text { ших образовательные программы по предметам начально- } \\
\text { го общего, основного общего, среднего общего образова- } \\
\text { ния, от общей численности обучающихся образовательных } \\
\text { организаций, } \%\end{array}$ & 46 & 47 & 48 \\
\hline 2 & $\begin{array}{l}\text { Доля одаренных детей, принимающих участие в различно- } \\
\text { го уровня конкурсах, олимпиадах (поддержка талантливых } \\
\text { детей, повышение их творческих способностей), \% }\end{array}$ & 40 & 30 \\
\hline 4 & $\begin{array}{l}\text { Доля детей школьного возраста, охваченных дополнитель- } \\
\text { ным образованием от общего числа детей школьного воз- } \\
\text { раста, \% }\end{array}$ & 22,4 & 64 \\
\hline 5 & $\begin{array}{l}\text { Удельный вес детей в возрасте от 7 до 16 лет, охваченных } \\
\text { организованным отдыхом, оздоровлением от общего числа } \\
\text { детей в возрасте от 7 до 16 лет, \% }\end{array}$ & 63 & 65 \\
\hline
\end{tabular}

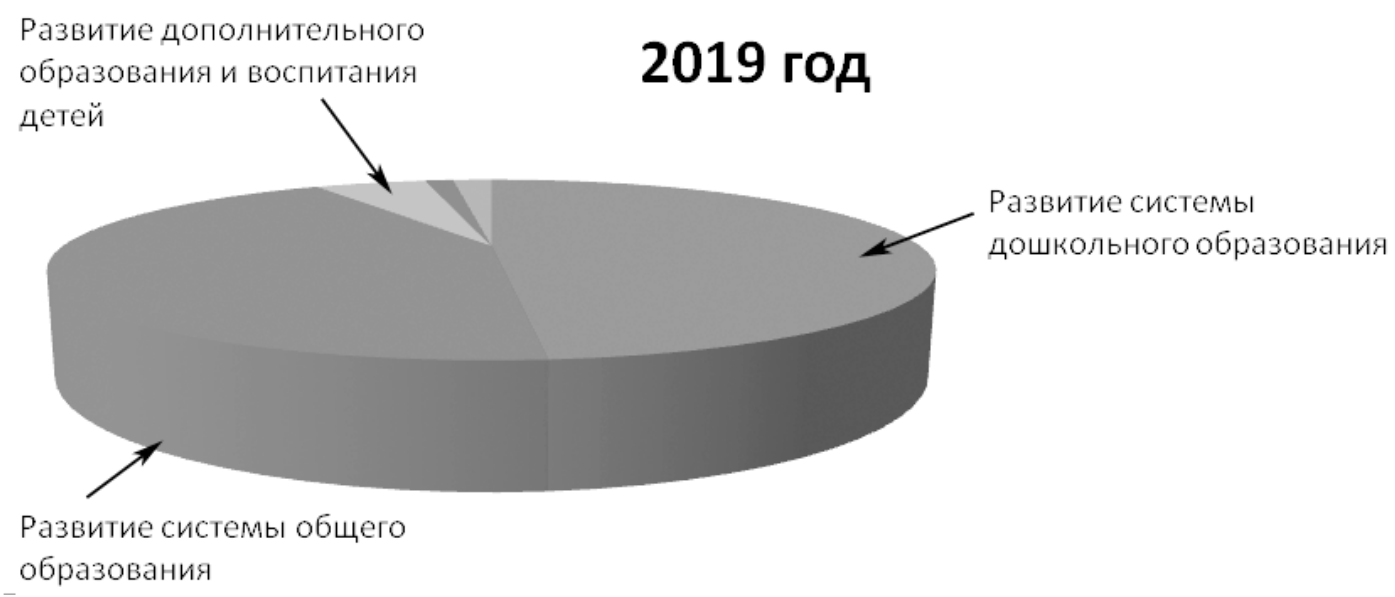

Рис. 3. Структура финансирования программы «Развитие образования города Элиста» в разрезе подпрограмм, \% 
образование, и меры поддержки одаренных детей, и развитие системы оздоровления, организованного отдыха и другие направления образования и развития творческой личности (табл. 1).

Данные показатели, по нашему мнению, более объективно отражают результаты реализации муниципальной программы, однако требуют совершенствования методики в части определения индикаторов оценки.

Данная проблема рассматривается государственными органами, и, возможно, будет разработана единая система оценки, которая позволит объективно оценивать использование финансовых средств при реализации муниципальных программ.

Заключение. Проведенные исследования показали, что в городском муниципальном образовании г. Элиста на протяжении последних лет применяется программноцелевой метод планирования. Финансовое обеспечение муниципальных программ предусмотрено целевыми показателями, сформированными в паспортах девяти муниципальных программ, и отражено в структуре расходов.

Данные оценки эффективности реализации программ не всегда объективно отражают эффективность бюджетных расходов и требуют совершенствования, особенно в части формирования критериев или индикаторов оценки.

Мы считаем, что необходимо совершенствование методики оценки эффективности программ и, возможно, даже разработки единых критериев их оценки.

\section{Литература}

1. Российская Федерация. Бюджетный кодекс РФ: офиц. текст от 31.07.1998 г. №145Ф3 (ред. от 04.06.2018 г.) (принят Гос. Думой 17 июля 1998 г;; одобр. Советом Федерации 17 июля 1998 г.). - М.: Эксмо, 2018. - 320 с.

2. Постановление Администрации г. Элиста от 29 декабря 2018 г. №2907 «Об утверждении муниципальной программы "Развитие образования города Элиста на 2019-2024 годы”» (с изменениями на 31 декабря 2019 г.) (в ред. Постановления Администрации г. Элиста От 31.12.2019 г. №2451).
3. Решение Элистинского городского Собрания от 27 декабря 2017 г. №3 «О бюджете города Элиста на 2018 год и на плановый период 2019 и 2020 годов».

4. Решение Элистинского городского Собрания от 26 декабря 2018 г. №1 «О бюджете города Элиста на 2019 год и на плановый период 2020 и 2021 годов».

5. Курепина Н. Л., Баглеева Г.В. Бюджетное обеспечение муниципальных программ, обеспечивающих социальную сферу Элисты// В сборнике: Векторы развития человеческого капитала в системе обеспечения экономической безопасности региона в постпандемической реальности. - Элиста, 2020. C. $124-127$.

6. Лавров А.М., Бегчин Н.А. Проблемы и перспективы внедрения «программных» бюджетов // Финансы. - 2016. - №4. C. 3-12.

7. Мысляева И. Н. Государственные и муниципальные финансы: учебник / И.Н. Мысляева. - М.: Издательство ИНФРА-М, 2008. - $360 \mathrm{c}$.

8. Соколов И.А., Бегчин Н.А., Беленчук $A$. A. Направления развития программноцелевого управления бюджетными средствами в России // Финансы. - 2015. - №4. C. 8-15.

9. Чулков А.С. Программно-целевое бюджетирование на региональном и местном уровнях // Финансы. - 2014. - №3. C. 17-24.

10. Финансы / под. ред. проф. М. В. Романовского, проф. О.В. Врублевской. - М.: Издательство Юрайт ИД Юрайт, 2012. - 590 с.

11. Официальный сайт Администрации г. Элиста [Электронный ресурс]. - Режим доступа: http://www. gorod-elista.ru.

\section{References}

1. Rossijskaja Federacija. Bjudzhetnyj kodeks RF: ofic. tekst ot 31.07.1998 g. №145-FZ (red. ot 04.06.2018 g.) (prinjat Gos. Dumoj 17 ijulja 1998 g.; odobr. Sovetom Federacii 17 ijulja 1998 g.) [Russian Federation. Budget Code of the Russian Federation: ofic. text of 31.07.1998 №145-FZ (as amended on 04.06.2018) (adopted by the State Duma on July 17, 1998; approved. by the Federation Council on July 17, 1998)]. Moscow: Jeksmo, 2018. - 320 p. 
2. Postanovlenie Administracii g. Jelista ot 29 dekabrja 2018 g. №2907 «Ob utverzhdenii municipal'noj programmy "Razvitie obrazovanija goroda Jelista na 2019-2024 gody"» (s izmenenijami na 31 dekabrja 2019 g.) (v red. Postanovlenija Administracii g. Jelista ot 31.12.2019 g. №2451) [Resolution of the Administration of the city of Elista of December 29, 2018 №2907 «On approval of the municipal program»" "Development of Education of the city of Elista for 2019-2024"» (as amended on December 31, 2019) (as amended. Resolutions of the Administration of the city of Elista of 31.12.2019 №2451)].

3. Reshenie Jelistinskogo gorodskogo Sobranija ot 27 dekabrja 2017 g. №3 «O bjudzhete goroda Jelista na 2018 god i na planovyj period 2019 i 2020 godov» [Decision of the Elista City Assembly of December 27, 2017 №3 «On the budget of the city of Elista for 2018 and for the planning period of 2019 and 2020»].

4. Reshenie Jelistinskogo gorodskogo Sobranija ot 26 dekabrja 2018 g. №1 «O bjudzhete goroda Jelista na 2019 god i na planovyj period 2020 i 2021 godov» [Decision of the Elista City Assembly of December 26, 2018 №1 «On the budget of the city of Elista for 2019 and for the planning period of 2020 and 2021»].

5. Kurepina N.L., Bagleeva G.V. Bjudzhetnoe obespechenie municipal'nyh programm, obespechivajushhih social'nuju sferu Jelisty [Budget support of municipal programs that provide the social sphere of Elista] // V sbornike: Vektory razvitija chelovecheskogo kapitala v sis- teme obespechenija jekonomicheskoj bezopasnosti regiona $\mathrm{v}$ postpandemicheskoj real'nosti [In the collection: Vectors of human capital development in the system of ensuring the economic security of the region in the post-pandemic reality]. - Elista, 2020. - Pp. 124-127.

6. Lavrov A.M., Begchin N.A. Problemy i perspektivy vnedrenija «programmnyh» bjudzhetov [Problems and prospects of implementing «program» budgets] // Finansy. 2016. - №4. - Pp. 3-12.

7. Mysljaeva I.N. Gosudarstvennye i municipal'nye finansy: uchebnik [State and municipal finance: textbook] / I. N. Mysljaeva. - Moscow: Izdatel'stvo INFRA-M, 2008. - $360 \mathrm{p}$.

8. SokolovI.A., Begchin N.A., BelenchukA.A. Napravlenija razvitija programmnocelevogo upravlenija bjudzhetnymi sredstvami v Rossii [Directions of development of programtarget management of budget funds in Russia] // Finansy [Finance]. - 2015. - №4. - Pp. 8-15.

9. Chulkov A.S. Programmno-celevoe bjudzhetirovanie na regional'nom i mestnom urovnjah [Program-target budgeting at the regional and local levels] // Finansy [Finance]. — 2014. №3. - Pp. 17-24.

10. Finansy [Finance] / In prof. M. V. Romanovskiy, prof. O.V. Vrublevskaya (eds.). Moscow: Izdatel'stvo Jurajt ID Jurajt, 2012. $590 \mathrm{p}$.

11. Oficial'nyj sajt Administracii g. Jelista [Official website of the Administration of Elista] [Jelektronnyj resurs]. - URL: http://www. gorod-elista.ru. 


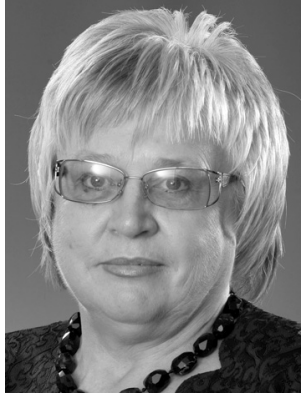

Курепина Наталья Леонидовна - доктор экономических наук, профессор кафедры экономической безопасности, учета и финансов экономического факультета Калмыцкого государственного университета им. Б. Б. Городовикова, Заслуженный деятель науки Республики Калмыкия.

Kurepina Natalia Leonidovna - Doctor of Economic Sciences, Professor of the Department of Economic Security, Accounting and Finance of the Economic faculty, Kalmyk State University named after B.B. Gorodovikov, Honored scientist of the Republic of Kalmykia.

358011, г. Элиста, пр. им. О. И. Городовикова, 3

3 O. I. Gorodovikova av., 358011, Elista, Russia

E-mail: kurepinanl@mail.ru

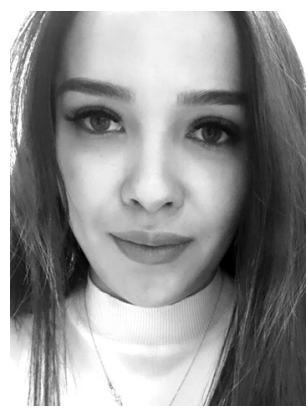

Баглеева Галина Валерьевна - магистрант Калмыцкого государственного университета им. Б. Б. Городовикова.

Bagleeva Galina Valerievna - Master's student, Kalmyk State University named after B. B. Gorodovikov.

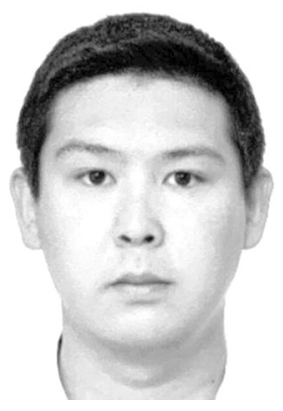

Асанов Тимур Николаевич - магистрант Калмыцкого государственного университета им. Б. Б. Городовикова.

Asanov Timur Nickolaevich - Master's student, Kalmyk State University named after B. B. Gorodovikov.

358011, г. Элиста, пр. им. О. И. Городовикова, 3

3 O. I. Gorodovikova av., 358011, Elista, Russia

E-mail: kurepinanl@mail.ru 